Research Institute for Quantitative Studies in Economics and Population Faculty of Social Sciences, McMaster University

Hamilton, Ontario, Canada

L8S 4M4

\title{
THE EDUCATION PREMIUM IN CANADA AND THE UNITED STATES
}

J.B. Burbidge, L. Magee, A.L. Robb

QSEP Research Report No. 364

October 2001

L. Magee and A.L. Robb are QSEP Research Associates and all authors are members of the McMaster Department of Economics.

This report is cross-listed as No. 60 in the McMaster University SEDAP Research Paper Series.

The Research Institute for Quantitative Studies in Economics and Population (QSEP) is an interdisciplinary institute established at McMaster University to encourage and facilitate theoretical and empirical studies in economics, population, and related fields. For further information about QSEP and other reports in this series, see our web site http://socserv2.mcmaster.ca/ qsep. The Research Report series provides a vehicle for distributing the results of studies undertaken by QSEP associates. Authors take full responsibility for all expressions of opinion. 


\title{
The Education Premium in Canada and the United States
}

\author{
J.B. Burbidge \\ L. Magee \\ A.L. Robb \\ Department of Economics \\ McMaster University \\ Hamilton, ON L8S 4M4 \\ CANADA \\ Email burbidge@mcmaster.ca
}

September 2001

We thank Tom Crossley, Jean Fares and Byron Spencer for helpful discussions, participant s in seminars at the SEDAP Conference (April 2001) and York University (June 2001) for comments, and SEDAP and SSHRCC for financial support. 


\title{
The Education Premium in Canada and the United States
}

\author{
Abstract \\ It is well known that in the United States the education premium - the ratio of the earnings of \\ university graduates to the earnings of high school graduates - has risen sharply in the last twenty \\ years. Some Canadian economists and policy makers presume the same fact holds in Canada. \\ Since so much of modern growth theory and micro and macro economic policy turns on the \\ education premium it is important for social scientists and policy makers to know what has \\ actually happened to the education premium. This paper argues that on the basis of available \\ evidence over the last twenty years the premium has been constant or has fallen in Canada.
}




\section{The Education Premium in Canada and the United States}

\section{Introduction}

It is very well known that in the United States the education premium - the ratio of the earnings of university graduat es to the earnings of high school graduates - has risen sharply in the last twenty years. This fact has been so well-publicized that some prominent Canadian economists simply presume the same fact holds in Canada and even labour economists are perhaps not as clear as they might be about the extent of inter-country difference in this aspect of wage structure. ${ }^{1}$ Since so much of modern growth theory and micro and macroeconomic policy turns on the education premium it is important for social scientists and policy makers to know what has actually happened to the education premium. This short paper argues that on the basis of available evidence over the last twenty years the premium has indeed risen sharply in the United States but it has been constant or has fallen in Canada.

We begin by looking at data drawn from the U.S. March Current Population Survey, 1981-1999, to show the reader what the fuss is all about. We then turn to an examination of "comparable" data for Canada. Part of this paper is absorbed with the issue of finding comparable Canadian data. Most would agree that the Canadian Survey of Consumer Finances provided data much like the U.S. CPS prior to 1998 - the last SCF was for the calendar year 1997. Currently it is unclear whether the most consistent time series is obtained by using SLID - the Survey of Labour Income Dynamics - or LFS - the Labour Force Survey - to extend the SCF-based earnings data beyond 1997. SLID is currently available for calendar years 1993 to 1998 and LFS earnings data is available for 1997-2000 so there is only one year - 1997 - when all three data sets overlap. We employ both SLID and LFS data to document what has happened to the education premium in Canada. ${ }^{2}$

\section{The Education Premium in the U.S.}

We focus on the real weekly earnings of women and men, aged 25 to 64, who work "fulltime," (that is, they typically work thirty or more hours per week), who are not self-employed and for whom the major source of income is wages and salaries. The "education premium", sometimes

${ }^{1}$ Card, Kramarz and Lemieux (1999) study the relative wages of skilled and unskilled workers in the United States, Canada and France using data for the 1980s. They conclude that “... relative wages appear to be slightly less flexible in Canada than in the United States ..." (p. 869).

${ }^{2}$ In Robb et al. (2001), we discuss the strengths and weaknesses of extending the SCF with either SLID or LFS. 
referred to as the "skill premium", is most often measured by the ratio of mean or median earnings of university graduates to the earning s of high school gra duates. For reasons that will become clear shortly we break our samples into six educational groups - elementary (EL), some high school (HS1), completed high school (HS2), some post-secondary (PS1), post-secondary certificate or diploma (PS2) and university degree (baccalaureate, or higher, UN). Since the education question differs across surveys, or may change over time for a given survey, and the UN category appears to be the one measured most consistently across surveys and over time, we have found it helpful to work with another measure of the education premium. This is the ratio of the earnings of university graduates, UN, to the earnings of everyone else, NONUN.

Table 1, which is based on the U.S. CPS, lists real median weekly earnings for the seven education groups for the period 1981 to $1999 .{ }^{3}$ For males, the median for completed high school (HS2) lies above the non-university (NONUN) median early in the data period but since the mid1980s the two data series are quite close, and trend downwards by about 12 percent. ${ }^{4}$ For females, HS2 and NONUN are close at the beginning of the data period while HS2 lies a bit below NONUN after 1990. Over the entire data period the two series trend upwards by an average of 13 percent. The medians for university trend sharply upwards. Between 1981 and 1999 male real earnings rose over 20 percent and female real earnings rose by 33 percent.

It is clear then that in the U.S., over our data period, real earnings decline more quickly or rise more slowly for lower education levels. Since there has been a marked increase in average years of education over the data period it is possible that the slow or negative growth in the real earnings of the less educated could be attributed to a shift over time across education groups. So, for example, in 1981, 9 percent of males had only an elementary education and 11 percent had some high school but had not completed high school. By 1999 these numbers had dropped to 4 and 8 percent. For females, the corresponding numbers are $(6,10)$ to $(3,6)$. If it were true that those in the lower education groups were drawn from successively lower sections of the ability distribution, over time median real earnings might fall for these groups. For our data period, however, the percentage with a university degree rose only slightly for males (25 to 28 percent). For females, it oscillated between 20 and 25 percent. By concentrating on the university-nonuniversity classification not only can we cope more easily with different data sets, as noted above, but we hope we are also less exposed to the criticism that changes in earnings ratios are driven largely by the changing composition of our sample. ${ }^{5}$ The last two columns of Table 1 show university earnings ratios measured two ways - relative to high school completed (UN/HS2) and

${ }^{3}$ The BLS changed the way in which the data were processed in 1988 and released two data files for this year. In the context of the present paper the two sets of 1988 earnings numbers are very close and we report the averages of the medians in Table 1.

${ }^{4}$ Note that there are two columns for UN and NONUN. The first is real weekly earnings; the second is an index of this time series with the number for 1981 set equal to 100 .

${ }^{5}$ Of course, the composition of the non-university sample has changed a great deal. 
relative to non- university (UN/NONUN). Although the two series vary so mewhat year to year the trends in them over our data period are very similar for both sexes.

Accordingly, the CPS-lines in Figures 1a and 1b graph the ratio of median earnings for university graduates relative to median earnings for non-university, that is, the last column of Table 1. For U.S. females the earnings ratio rises from 1.5 in 1981 to nearly 1.8 in 1998. For males, the end point is about the same but the ratio starts lower in 1981 at 1.3. It is clear then that in the U.S., for both sexes, the education premium has risen sharply. Does the earnings structure in Canada resemble the U.S. in this respect?

\section{Using the SCF to Study the Education Premium in Canada}

Statistics Canada's Survey of Consumer Finances was very similar in structure and content to the U.S. Current Population Survey. Between 1981 and 1997, with the exception of 1983, the SCF produced annually public use files on individuals' incomes and characteristics. While many of the questions differed between the SCF and CPS it is possible to extract Canadian samples much like the U.S. data sets analysed above.

Tables $2 \mathrm{a}$ and $2 \mathrm{~b}$ are the Canadian counterparts of Table 1 . Figures $1 \mathrm{a}$ and $1 \mathrm{~b}$ graph time series earnings ratios for both countries. For Canadian males, real earnings fall for all education groups and, at roughly the same rate. For Canadian females, UN is remarkable stable and NONUN rises by about 10 percent. It is not surprising, therefore, that the university-education premia shown in the last two columns of these tables do not exhibit an upward trend over the 1981-1997 period; indeed, UN/NONUN trends downward for females.

In an important sense the paper could end here. On the basis of these two surveys - the CPS for the U.S. and the SCF for Canada - the education premium has increased markedly in the U.S. but has been very stable or perhaps even declined slightly in Canada. As time go es by, how ever, the gap between the termination of the SCF (1997) and the latest CPS data (currently 1999) will grow. Therefore, it seems, to us at least, important to try to extend the Canadian data beyond 1997, the last year of SCF data. Is this possible?

\section{Extending the SCF - SLID and LFS}

Longitudinal data sets are rare in Canada. In the late 1980s and early 1990s Canadian researchers clamoured for a longitudinal data set like the Panel Study on Income Dynamics (PSID) in the U.S. In response Statistic s Canada introduced the Survey of Labour Income Dynamics. A group of individuals and families were interviewed for the first time in 1994 about their incomes in 1993 and they were followed for another five years. The people they married were introduced into the panel and as some members of the panel attrited new people were added to the cross-sections. Thus some of the people in SLID dat a sets are members of a panel and 
others are not. While some of the questions asked in SLID are quite different from tho se in the SCF, SLID is the survey that was and is still intended as a replacement for (improvement over) the SCF. The wage and salary information in the SCF should be the same as that in SLID. Both surveys asked people to report wages and salaries from all jobs including any tips or gratuities or overtime. SLID has been conducted every year since 1994 and earnings data are currently available for calendar years 1993-1998. A second wave started by reporting 1996 incomes and components so currently we have access to complete information on the first wave and three years of data on the second wave.

It is less well known that the Labour Force Survey began collecting earnings information in January 1997. LFS earnings questions are designed to minimize non-response by allowing respondents to report earnings at the time of the survey in a way that is easiest for them. Those paid by the hour are asked to report an hourly wage rate that includes tips, commissions and bonuses. Unfortunately, neither the questionnaire nor the guidelines produced by Statistics Canada mention overtime earnings. The later questions on hours worked distinguish actual hours worked from usual hours and overtime hours. Those not paid by the hour can report the ir earnings weekly, bi-weekly, semi-monthly, monthly or yearly. From the earnings and hours information collected Statistics Canada calculates an hourly wage rate. Multiplying this wage rate by usual hours worked per week one can obtain an estimate of weekly earnings. For salaried employees this should be close to SCF or SLID estimates of weekly earnings. For those paid by the hour LFS may lie below SCF and SLID because overtime earnings may not be included. In addition, LFS earnings estimates ignore earnings from secondary jobs whereas SCF and SLID asked respondents to report all earnings. LFS earnings questions are asked at the first interview and then updated in subsequent interviews only if the person changed jobs.

Unlike SCF and SLID, the LFS does not ask questions about weeks worked in the previous calendar year so one cannot obtain annual earnings from the LFS. But by using reported weeks worked in the SCF and the SLID one can produce estimates of weekly earnings for all three data sets. We feel these estimates of week ly earnings offer the best chance at a relatively consistent time series of earnings, 1981 to date.

It is, of course, important not only to achieve consistency in earnings but also in education categories. In earlier work we have discussed this issue at length with regard to the SCF (see BarOr et al. (1995), Burbidge, Magee and Robb (1997)). The SCF education question changed in 1988 and it is well known that it is impossible to arrange education categories so that there is no break in the time series for these two years. Tables $3 \mathrm{a}$ and $3 \mathrm{~b}$ illustrate this point; we see bigger changes 1988-1989 than in any other pair of years. We are indebted to Jean Fares of the Bank of Canada for pointing out to us that it is possible to set up the six education categories we have in this paper to achieve comparability between the SCF and the LFS. To do this one uses the summary education question in the SCF to create EL, HS1, HS2, PS1, PS2 and UN, and the education question in the LFS maps naturally into these six categories. Inspection of Tables 3a and $3 \mathrm{~b}$ show that for the one overlap year we have - 1997 - the percentages are very close. One 
might be tempted then to guess that the SCF time series of earnings by education could be accurately extended by using the LFS. But Tables $2 \mathrm{a}$ and $2 \mathrm{~b}$, which report median weekly earnings by education, for the SCF, SLID and the LFS raise some doubt. Given our earlier discussion it is not surprising to see that LFS median earnings tend to be lower than SCF or SLID estimates, particularly for males. Still, earnings ratios may be measured consistently acro ss the three data sets. Inspection of the three Canadian data series in Figures 1a and $1 \mathrm{~b}$ offer some support for this view. The only outliers are the first three years of SLID data for females. Interestingly, this anomaly would disappears if were to graph UN/HS2 rather than UN/NONUN (see Table 2b).

Thus, from the point of view of the focus of this paper - the behaviour of education premium in the U.S. and Canada - it probably does not matter whether one uses the LFS or SLID to extend the SCF. ${ }^{6}$ For males, the Canadian education premium has recently been at or near 1.40 , 0.37 below the 1999 number for the U.S. ${ }^{7}$ For females, the education premium has trended downwards from about 1.65 to 1.50 . By contrast, the U.S. premium starts at 1.50 in 1981, crosses the Canadian line in the mid-eighties and rises to about 1.75 in 1999.

\section{Conclusions}

The Canadian and U.S. economies are similar in many ways but the behaviour of the real earnings of university graduates relative to the real earnings of other educational gro ups is completely different. Further research is needed to better understand why the behaviour of relative earnings across education groups is so different. But however our understanding is advanced by this research it is quite possible that economic models and policies that are appropriate for the U.S. may be quite inappropriate for Canada.

${ }^{6}$ For a more thorough analysis see Robb et al. (2001).

${ }^{7}$ Georges Monette of York University pointed out to us that one cannot treat a time series of cro ss-sectional numbers in the same way as a time series on panel data. Time series of medians or means or other statistics from panel data are bound to be smo other than the corresponding time series from cross-sectional data sets. 


\section{References}

Y. Bar-Or, J.B. Burbidge, L. Magee and A.L. Robb (1995) "The Wage Premium to a University Education in Canada: 1971-1991," Journal of Labor Economics, 13, pp. 762-794.

J.B. Burbidge, L. Magee and A.L. Robb (1997) "Canadian Wage Inequality Over the Last Two Decades,” Empirical Economics, 22, pp. 181-203.

D. Card, F. Kramarz and T. Lemieux (1999) "Changes in the Relative Structure of Wages and Employment: A Comparison of the United States, Canada and France," Canadian Journal of Economics, 32, pp. 843-877.

A.L. Robb, L. Magee, J.B. Burbidge (2001) "Wages in Canada: SCF, SLID, LFS and the Skill Premium," McMaster University, mimeo. 
Table 1: Median Weekly Earnings by Education (1997 dollars):

U.S. Males and Females, Aged 25-64; CPS

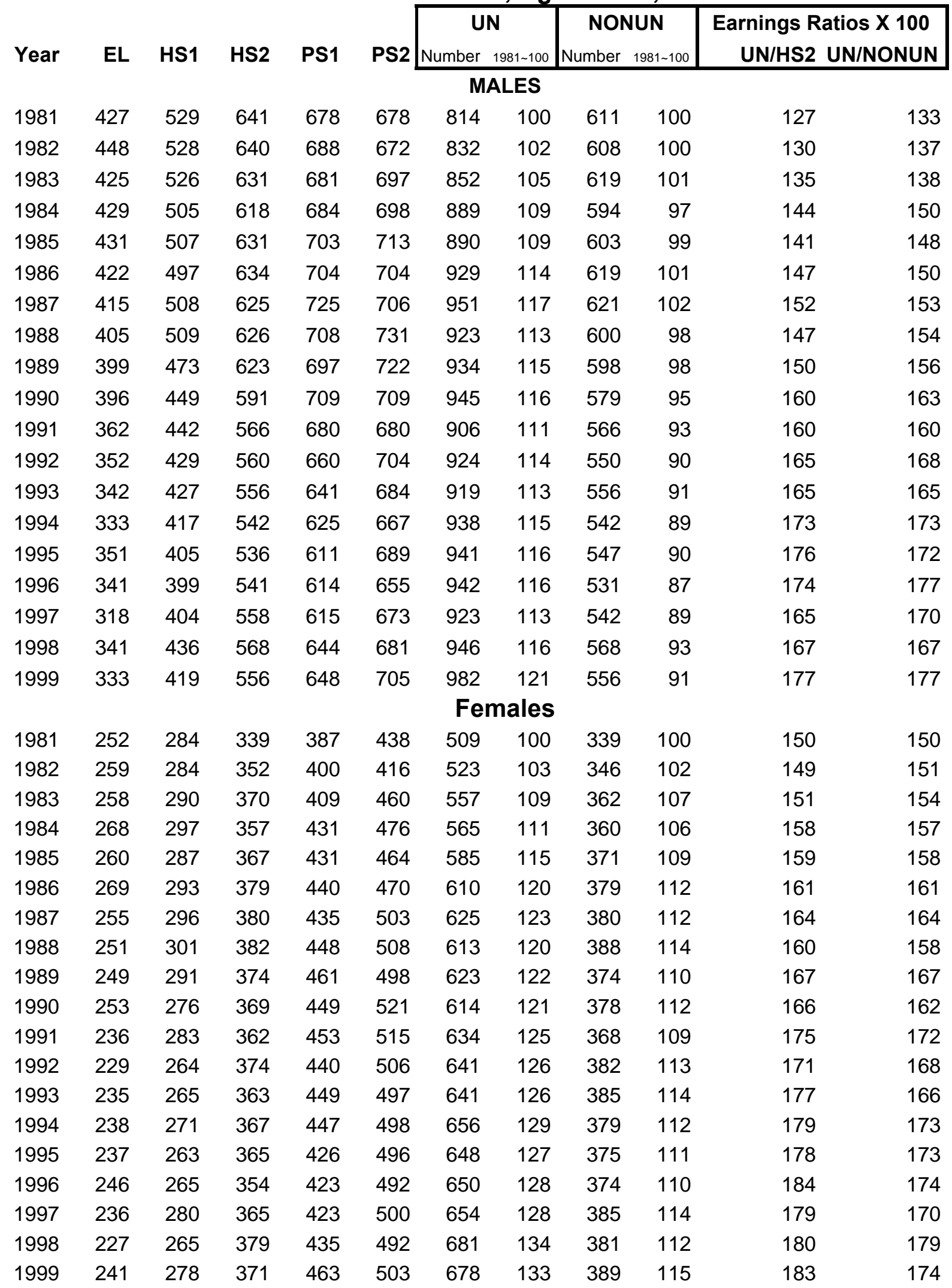


Table 2a: Median Weekly Earnings by Education (1997 dollars):

Canadian Males Aged 25-64; SCF, SLID and LFS

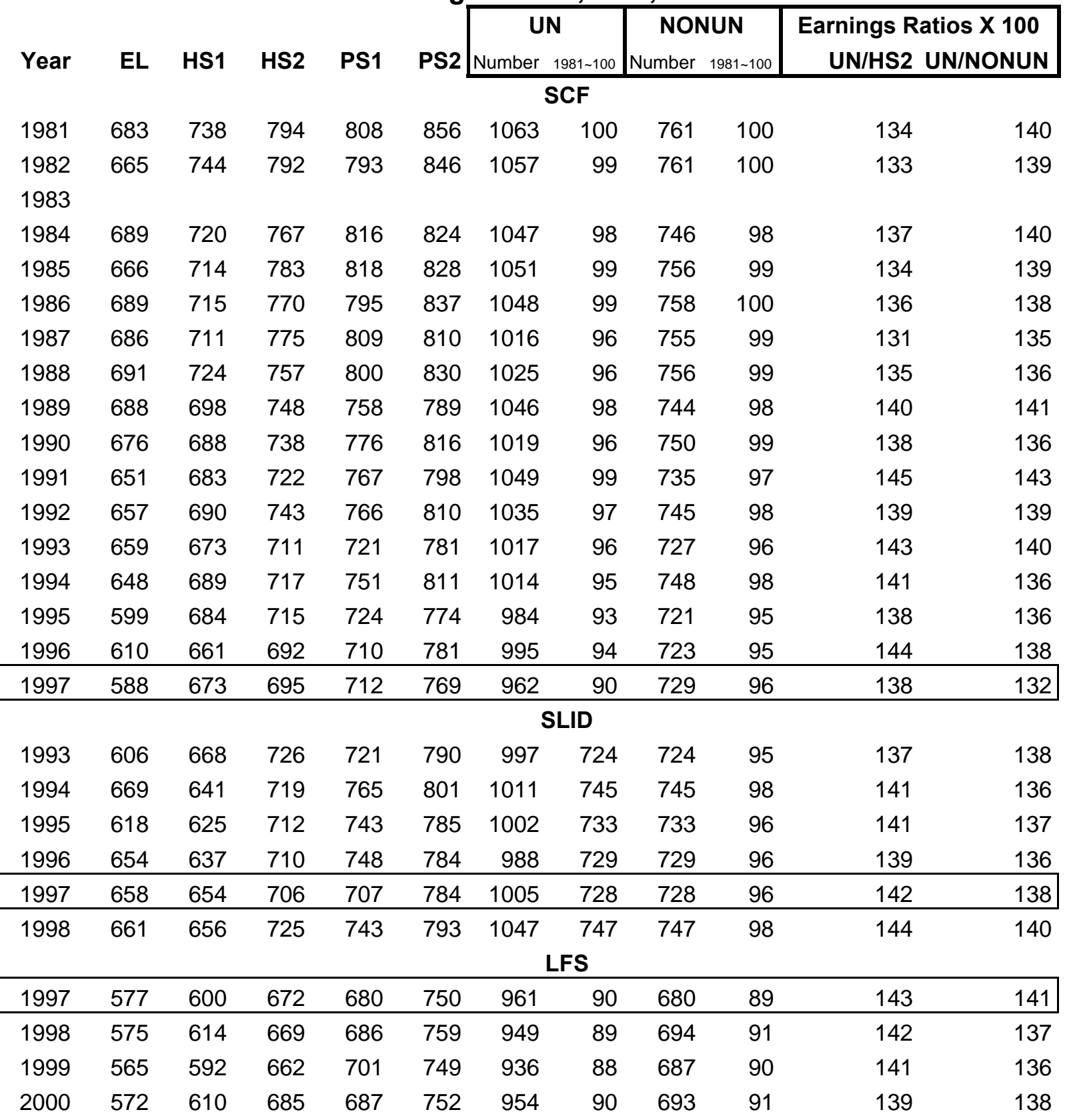


Table 2b: Median Weekly Earnings by Education (1997 dollars)

Canadian Females Aged 25-64; SCF, SLID and LFS

\begin{tabular}{|c|c|c|c|c|c|c|c|c|c|c|c|}
\hline \multirow[b]{2}{*}{ Year } & \multirow[b]{2}{*}{ EL } & \multirow[b]{2}{*}{ HS1 } & \multirow[b]{2}{*}{ HS2 } & \multirow[b]{2}{*}{ PS1 } & \multirow[b]{2}{*}{ PS2 } & \multicolumn{2}{|c|}{ UN } & \multicolumn{2}{|c|}{ NONUN } & \multicolumn{2}{|c|}{ Earnings Ratios X 100} \\
\hline & & & & & & Number & $1981 \sim 100$ & Number & $1981 \sim 100$ & UN/HS2 & UN/NONUN \\
\hline \multicolumn{12}{|c|}{ SCF } \\
\hline 1981 & 366 & 429 & 492 & 524 & 561 & 776 & 100 & 471 & 100 & 158 & 165 \\
\hline 1982 & 380 & 427 & 482 & 515 & 551 & 786 & 101 & 469 & 100 & 163 & 168 \\
\hline \multicolumn{12}{|l|}{1983} \\
\hline 1984 & 366 & 430 & 488 & 511 & 574 & 775 & 100 & 472 & 100 & 159 & 164 \\
\hline 1985 & 363 & 414 & 481 & 513 & 552 & 773 & 100 & 469 & 100 & 161 & 165 \\
\hline 1986 & 371 & 418 & 494 & 530 & 554 & 768 & 99 & 482 & 102 & 155 & 159 \\
\hline 1987 & 364 & 418 & 493 & 508 & 558 & 762 & 98 & 481 & 102 & 155 & 158 \\
\hline 1988 & 387 & 416 & 480 & 508 & 546 & 768 & 99 & 474 & 101 & 160 & 162 \\
\hline 1989 & 350 & 418 & 488 & 476 & 535 & 796 & 103 & 475 & 101 & 163 & 168 \\
\hline 1990 & 409 & 403 & 493 & 508 & 554 & 776 & 100 & 490 & 104 & 157 & 158 \\
\hline 1991 & 357 & 420 & 497 & 522 & 546 & 807 & 104 & 501 & 106 & 162 & 161 \\
\hline 1992 & 376 & 430 & 517 & 517 & 563 & 828 & 107 & 517 & 110 & 160 & 160 \\
\hline 1993 & 407 & 418 & 496 & 508 & 549 & 793 & 102 & 499 & 106 & 160 & 159 \\
\hline 1994 & 368 & 406 & 507 & 533 & 550 & 802 & 103 & 507 & 108 & 158 & 158 \\
\hline 1995 & 379 & 431 & 497 & 516 & 549 & 794 & 102 & 506 & 107 & 160 & 157 \\
\hline 1996 & 404 & 430 & 508 & 511 & 547 & 782 & 101 & 508 & 108 & 154 & 154 \\
\hline 1997 & 384 & 432 & 504 & 558 & 556 & 788 & 102 & 519 & 110 & 156 & 152 \\
\hline \multicolumn{12}{|c|}{ SLID } \\
\hline 1993 & 339 & 459 & 524 & 555 & 565 & 802 & 532 & 532 & 113 & 153 & 151 \\
\hline 1994 & 358 & 448 & 498 & 547 & 577 & 771 & 533 & 533 & 113 & 155 & 145 \\
\hline 1995 & 366 & 428 & 504 & 539 & 585 & 764 & 539 & 539 & 114 & 152 & 142 \\
\hline 1996 & 363 & 410 & 498 & 531 & 556 & 793 & 518 & 518 & 110 & 159 & 153 \\
\hline 1997 & 325 & 410 & 498 & 530 & 556 & 795 & 516 & 516 & 110 & 159 & 154 \\
\hline 1998 & 343 & 414 & 512 & 542 & 560 & 804 & 528 & 528 & 112 & 157 & 152 \\
\hline \multicolumn{12}{|c|}{ LFS } \\
\hline 1997 & 360 & 400 & 495 & 519 & 554 & 769 & 99 & 500 & 106 & 155 & 154 \\
\hline 1998 & 355 & 396 & 495 & 525 & 552 & 762 & 98 & 503 & 107 & 154 & 151 \\
\hline 1999 & 351 & 383 & 487 & 539 & 548 & 750 & 97 & 504 & 107 & 154 & 149 \\
\hline 2000 & 349 & 387 & 489 & 532 & 550 & 752 & 97 & 502 & 107 & 154 & 150 \\
\hline
\end{tabular}


Table 3a: Percentage Distributions Across Education Categories:

Canadian Males Aged 25-64; SCF, SLID and LFS

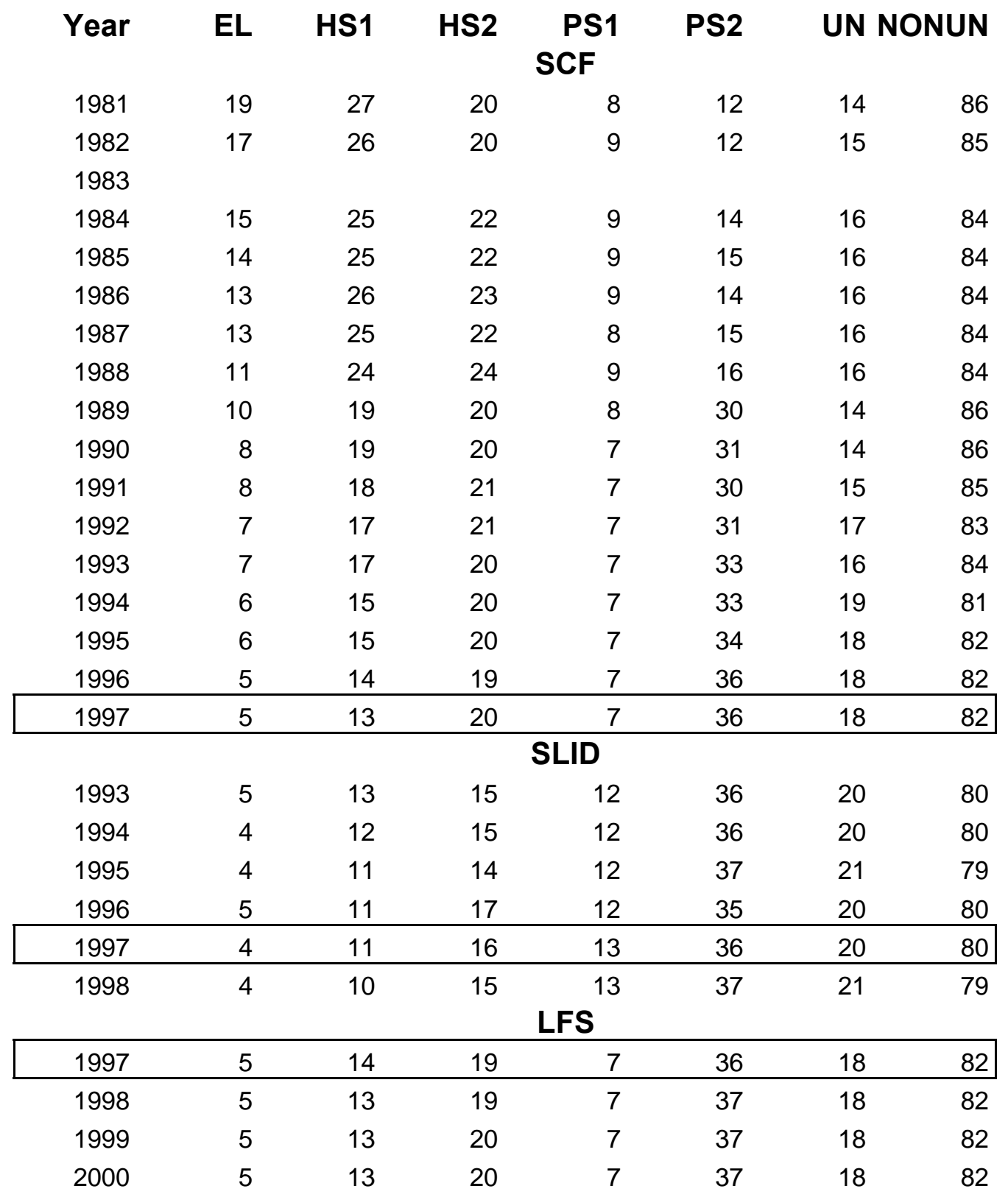


Table 3b: Percentage Distributions Across Education Categories:

\section{Canadian Females Aged 25-64; SCF, SLID and LFS}

\begin{tabular}{|c|c|c|c|c|c|c|c|}
\hline Year & EL & \multicolumn{4}{|c|}{ SCF } & \multicolumn{2}{|c|}{ UN NONUN } \\
\hline 1981 & 12 & 25 & 25 & 9 & 17 & 12 & 88 \\
\hline 1982 & 11 & 24 & 26 & 9 & 17 & 13 & 87 \\
\hline \multicolumn{8}{|l|}{1983} \\
\hline 1984 & 9 & 22 & 26 & 9 & 18 & 16 & 84 \\
\hline 1985 & 8 & 22 & 27 & 9 & 19 & 16 & 84 \\
\hline 1986 & 7 & 22 & 28 & 10 & 19 & 16 & 84 \\
\hline 1987 & 8 & 22 & 26 & 9 & 20 & 15 & 85 \\
\hline 1988 & 7 & 21 & 27 & 9 & 20 & 16 & 84 \\
\hline 1989 & 6 & 17 & 24 & 8 & 31 & 14 & 86 \\
\hline 1990 & 5 & 17 & 25 & 8 & 32 & 13 & 87 \\
\hline 1991 & 5 & 14 & 25 & 8 & 32 & 15 & 85 \\
\hline 1992 & 4 & 13 & 25 & 8 & 33 & 16 & 84 \\
\hline 1993 & 4 & 13 & 24 & 8 & 35 & 16 & 84 \\
\hline 1994 & 4 & 11 & 23 & 8 & 36 & 19 & 81 \\
\hline 1995 & 4 & 11 & 23 & 8 & 36 & 18 & 82 \\
\hline 1996 & 3 & 10 & 21 & 8 & 37 & 20 & 80 \\
\hline 1997 & 3 & 10 & 21 & 8 & 38 & 20 & 80 \\
\hline \multicolumn{8}{|c|}{ SLID } \\
\hline 1993 & 3 & 9 & 17 & 11 & 41 & 19 & 81 \\
\hline 1994 & 3 & 8 & 17 & 11 & 41 & 20 & 80 \\
\hline 1995 & 3 & 7 & 15 & 12 & 41 & 22 & 78 \\
\hline 1996 & 3 & 8 & 20 & 11 & 38 & 20 & 80 \\
\hline 1997 & 3 & 8 & 19 & 11 & 39 & 20 & 80 \\
\hline 1998 & 3 & 7 & 17 & 11 & 40 & 22 & 78 \\
\hline \multicolumn{8}{|c|}{ LFS } \\
\hline 1997 & 3 & 10 & 22 & 8 & 38 & 19 & 81 \\
\hline 1998 & 3 & 10 & 22 & 8 & 38 & 19 & 81 \\
\hline 1999 & 3 & 10 & 22 & 8 & 38 & 20 & 80 \\
\hline 2000 & 3 & 9 & 22 & 8 & 38 & 20 & 80 \\
\hline
\end{tabular}




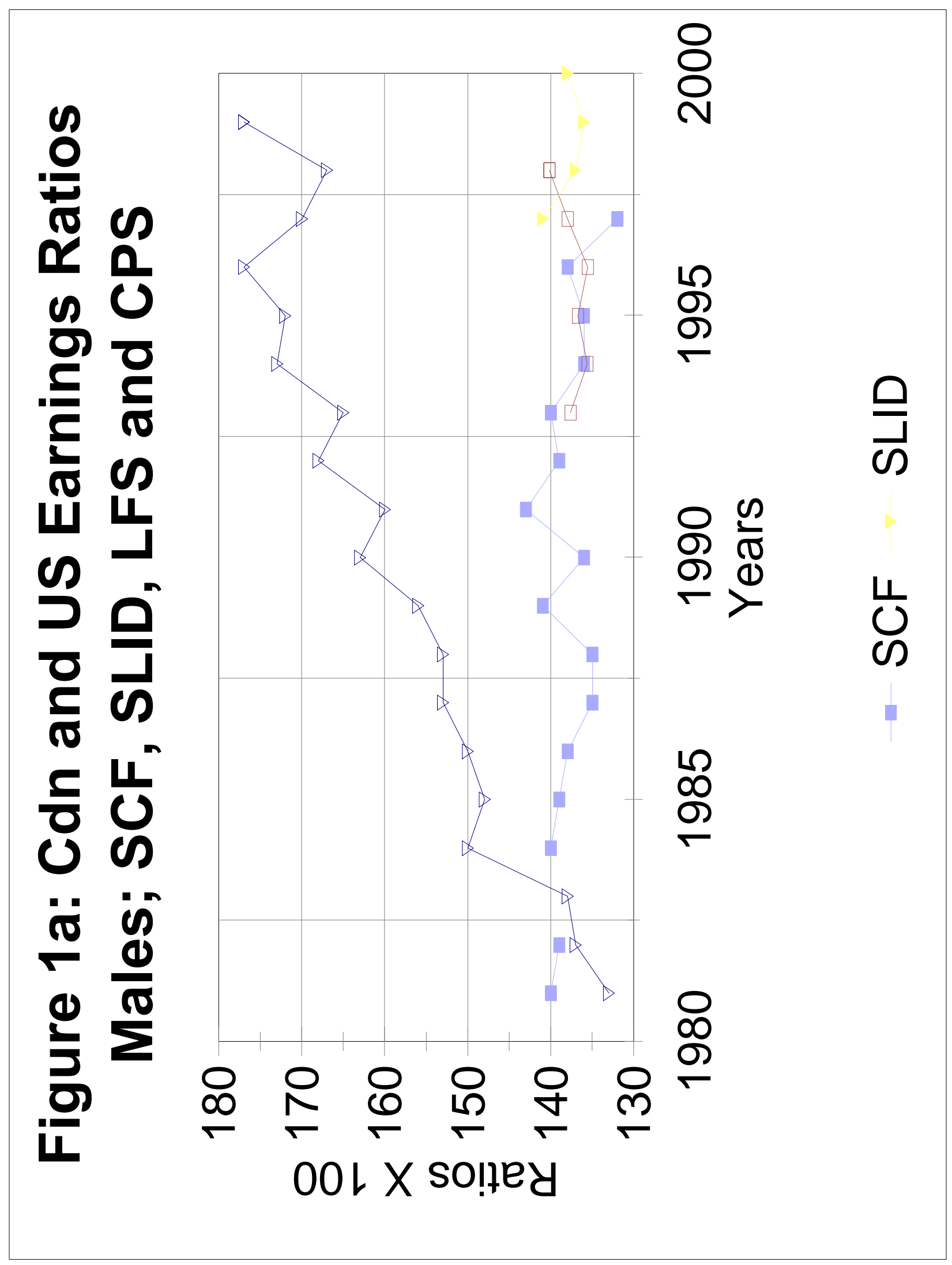




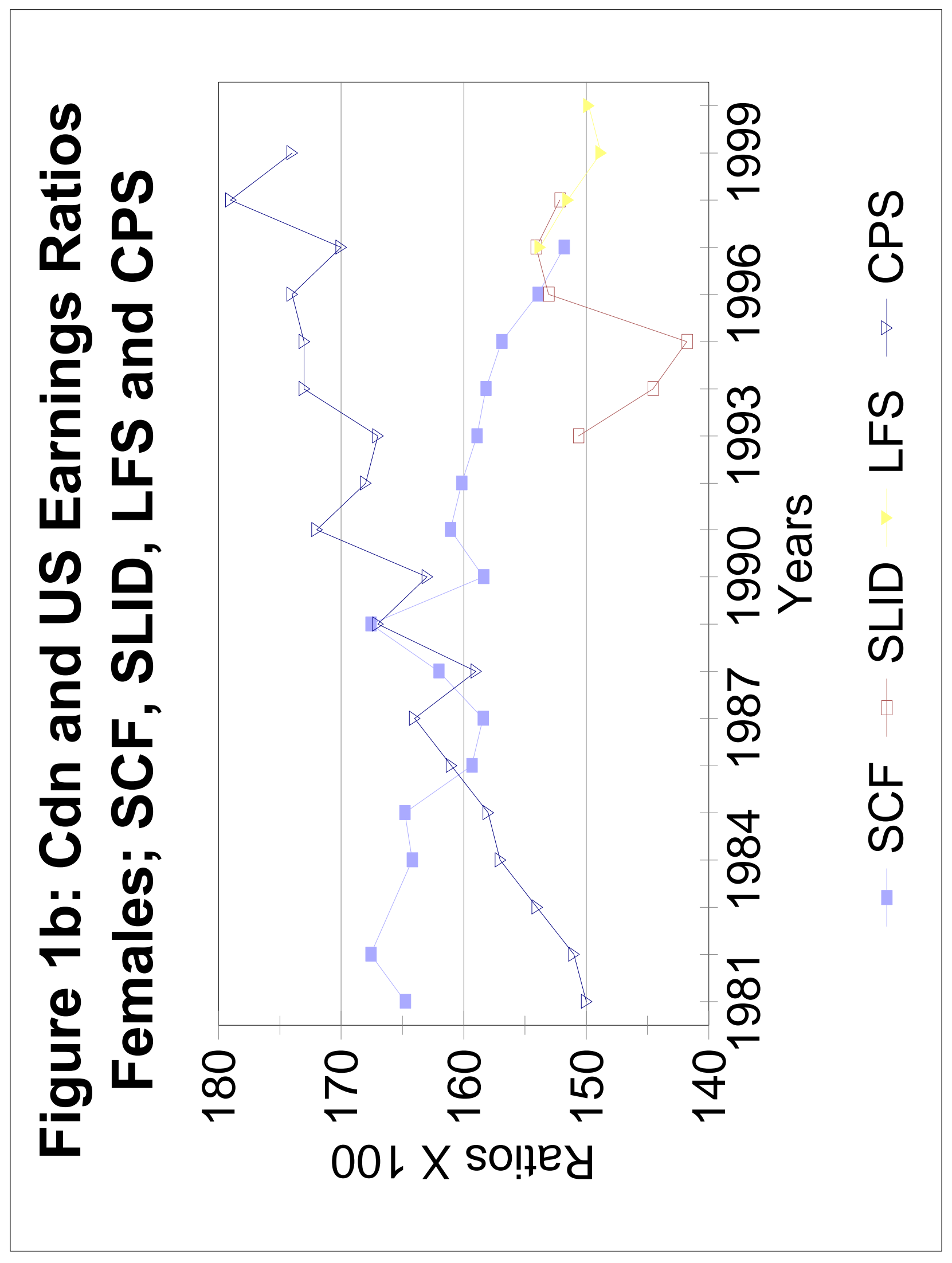


No. 338: A Bayesian Approach for Measuring Economies of Scale with Application to Large Canadian Banks

M.W.L. Chan

D. Li

D.C. Mountain

No. 339: Economic Costs of Population Aging

F.T. Denton

B.G. Spencer

No. 340: Population Aging and Its Economic Costs: A Survey of the

F.T. Denton Issues and Evidence

B.G. Spencer

No. 341: How Much Help is Exchanged in Families? Towards an Understanding of Discrepant Research Findings

C.J. Rosenthal

L.O. Stone

No. 342: Did Tax Flattening Affect RRSP Contributions?

M.R. Veall

No. 343: Families as Care-Providers Versus Care-Managers?

C.J. Rosenthal

Gender and Type of Care in a Sample of Employed

A. Martin-Matthews

Canadians

No. 344: Alternatives for Raising Living Standards

W. Scarth

No. 345: Mixed Estimation When the Model And/Or Stochastic

F.T. Denton

Restrictions are Nonlinear

No. 346: A Model of Energy Demand in the U.S. Commercial

F.T. Denton

Sector with Declining Rate Schedules

D.C. Mountain

B.G. Spencer

No. 347: Projections of the Population and Labour Force to 2046:

F.T. Denton

Canada

C.H. Feaver

B.G. Spencer

No. 348: Projections of the Population and Labour Force to 2046:

The Provinces and Territories

F.T. Denton

C.H. Feaver

B.G. Spencer

No. 349: Location of Adult Children as an Attraction for Black and White Elderly Migrants in the United States

K.-L. Liaw

W.H. Frey

J.-P. Lin

No. 350: The Effects of Drug Subsidies on Out-of-Pocket

T.F. Crossley

Prescription Drug Expenditures by Seniors: Regional

P. Grootendorst

Evidence from Canada

S. Korkmaz

M.R. Veall 
No. 351: Describing Disability among High and Low Income Status Older Adults in Canada

P. Raina

M. Wong

L.W. Chambers

M. Denton

A. Gafni

No. 352: Some Demographic Consequences of Revising the

F.T. Denton

Definition of 'Old' to Reflect Future Changes in Life Table

B.G. Spencer

Probabilities

No. 353: The Correlation Between Husband's and Wife's

Education: Canada, 1971-1996

L. Magee

J. Burbidge

L. Robb

No. 354: The Effect of Marginal Tax Rates on Taxable Income: A

M.-A. Sillamaa

Panel Study of the 1988 Tax Flattening in Canada

M.R. Veall

No. 355: Population Change and the Requirements for Physicians: The Case of Ontario

F.T. Denton

A. Gafni

B.G. Spencer

No. 356: $\quad 2 \frac{1}{2}$ Proposals to Save Social Security

D. Fretz

M.R. Veall

No. 357: The Consequences of Caregiving: Does Employment Make A Difference?

C.L. Kemp

C.J. Rosenthal

No. 358: Exploring the Effects of Population Change on the Costs of Physician Services

F.T. Denton

A. Gafni

B.G. Spencer

No. 359: Reflexive Planning for Later Life: A Conceptual Model and Evidence from Canada

M.A. Denton

S. French

A. Gafni

A. Joshi

C. Rosenthal

S. Webb

No. 360: Time Series Properties and Stochastic Forecasts: Some

F.T. Denton

Econometrics of Mortality from The Canadian Laboratory

C.H. Feaver

B.G. Spencer

No. 361: Linear Public Goods Experiments: A Meta-Analysis

J. Zelmer 
No. 362: The Timing and Duration of Women's Life Course Events:

K.M. Kobayashi

A Study of Mothers With At Least Two Children

A. Martin-Matthews

C.J. Rosenthal

S. Matthews

No. 363: Age-Gapped and Age-Condensed Lineages: Patterns of Intergenerational Age Structure among Canadian Families

A. Martin-Matthews

K.M. Kobayashi

C.J. Rosenthal

S.H. Matthews

No. 364: The Education Premium in Canada and the United States

J.B. Burbidge

L. Magee

A.L. Robb 